\title{
Spatial autocorrelation of genotypes in populations of Impatiens pallida and Impatiens capensis
}

\author{
Daniel J. Schoen and \\ Robert G. Latta
}

\author{
Department of Biology, McGill University, \\ 1205 Avenue Docteur Penfield, Montreal, Québec, \\ Canada H3A 1 B1.
}

\begin{abstract}
The genetic control and small scale spatial distributions of three conspicuous genetic polymorphisms--presence or absence of corolla spotting, yellow or white corolla colour, and presence or absence of stem waxiness-were studied in populations of the plant species Impatiens pallida and I. capensis occurring in Québec, Canada. The corolla spotting and colour morphs in $I$. pallida each appear to be determined by different pairs of unlinked loci. Dominant alleles at each locus pair are required for the expression of corolla spotting or yellow corolla colouration. Stem waxiness in $I$. capensis is also shown to be under genetic control. Significant clustering of identical flower and stem phenotypes at small interplant distances was observed in most population samples, suggesting substructuring of genotypes in space. The sizes of patches where morph frequencies occurred in excess of random expectations were found to be consistent among populations and polymorphisms within the species, lending support to the interpretation that substructuring of genetic variation in these populations is due to restricted gene dispersal. The population genetical consequences of limited gene flow in these species is discussed.
\end{abstract}

\section{INTRODUCTION}

Investigations of population substructure in plants have relied upon the study of the spatial distribution of conspicuous polymorphisms (Epling and Dobzhansky, 1942; Wright, 1943, 1978; Epperson and Clegg, 1986), as well as that of electrophoretically-detectable variation (Hamrick and Allard, 1972; Schaal, 1975; Ennos, 1985; Waser, 1987; Dewey and Heywood, 1988; Epperson and Allard, 1989). Such investigations have often, but not always, revealed significant departures from random spatial distribution of genotypes. For example, Schaal (1975) and Epperson and Clegg (1986) detected significant spatial association of genotypes in Liatris cylindracea and Ipomoea purpurea, but Ennos (1985), Epperson and Allard (1989) and Dewey and Heywood (1988) failed to find strong evidence of non-random spatial distribution of genotypes in populations of the grass Cynosurus cristatus, the lodgepole pine (Pinus contorta) and the tropical tree Psychotria nervosa, respectively. Significant departure from random spatial distribution of genotypes can be due to spatially-varying selection and/or to local dispersal of genes (Turner, Stephens, and Anderson, 1982; Bradshaw, 1984). Thus, for example, the discovery of population differentiation associated with discrete variation in the habitat has been interpreted as due to spatially-varying selection (Antonovics and Bradshaw, 1970; Linhart, 1974; Silander and Antonovics, 1979; Antlfinger, 1981), whereas the discovery of population substructure in the absence of any clear microenvironmental heterogeneity has been interpreted as due to local gene dispersal (Epperson and Clegg, 1986). Moreover, the absence of population substructure is sometimes taken as evidence that gene flow distances in the study population is not highly restricted (Epperson and Allard, 1989; Dewey ard Heywood, 1988), though other explanations for lack of spatial structure are also possible. For example, Epperson and Clegg (1986) suggested that a high mutation rate at the $\mathrm{W} / \mathrm{w}$ locus in $I$. purpurea masked spatial substructure when this locus alone was studied, and Dewey and Heywood (1988) and Epperson and Allard (1989) note that spatial substructure can go undetected if it exists as a scale smaller than that used for sampling between plants.

The existence of population genetic substructure is important to be aware of, as it may influence the pattern of genetic transmission within the population, and determine how the population 
responds to global selection (Epperson, 1989). In addition, the assumption of a lack of population substructure in cases where substructure is in fact present, can lead to biased estimates of mating system parameters (Ellstrand, Torres, and Levin, 1978; Ennos and Clegg, 1982; Ritland, 1985). Here we report evidence pertaining to the genetic control and degree of population substructure of three conspicuous polymorphisms in the species $I$. pallida and I. capensis. Previous work with I. pallida has revealed the existence of spatial heterogeneity in the magnitude and direction of phenotypic selection of a number of quantitative traits (Stewart and Schoen, 1987), as well as the presence of within-population differentiation of a number of quantitative traits (Schemske, 1984). We interpret the significance of the present findings in light of these earlier results.

\section{MATERIALS AND METHODS}

\section{Organisms and study site}

Impatiens pallida and I. capensis are common, annual plants which grow in forests throughout eastern North America (Schemske, 1978; Waller 1980). Plants of both species reproduce via cleistogamous and chasmogamous flowers, with the latter flower type typically being produced only on larger individuals. The I. pallida populations studied occurred on relatively dry ground in two separate valleys in a beech-maple forest at Mont St. Hilaire, Quebec, Canada (Maycock, 1961). The I. capensis populations occupied sites directly adjacent to streams or wet depressions at Mont St. Hilaire. Populations of both species occurred as dense, almost monospecific stands. Densities in the populations studied ranged from 80 to 300 plants per square metre.

Populations of I. pallida at Mont St. Hilaire are polymorphic for at least one of two distinct flower colour polymorphisms. These polymorphisms are the colouration of the chasmogamous corolla, either yellow or white, and the presence or absence of spotting in the corolla throat (fig. 1). Populations of I. capensis at Mont St. Hilaire are polymorphic for the presence or absence of a waxy bloom on the stem surface (fig. 1). We also noted variation in the degree of corolla spotting in $I$. capensis, though this variation was continuous as opposed to the more discrete variation associated with corolla spotting in I. pallida, and could not, therefore, be easily applied to the analysis of population substructure.

\section{Genetic studies of the flower and stem polymorphisms}

Parent plants used in crosses for analysing the genetic control of corolla spotting and corolla coloure in $I$. pallida, and stem waxiness in $I$. capensis, originated from seedlings that were harvested in May of 1987 from natural populations at Mont St. Hilaire. The I. pallida seedlings were brought into a screened insect exclosure located near the McGill University Biology Field Station at Mont St. Hilaire, while the I. capensis seedlings were grown in an adjacent garden plot. The plants were grown for approximately four months, during which time the crosses described below were carried out, and seed collections were made. To promote germination, harvested seeds were stored at $4^{\circ} \mathrm{C}$ between two layers of wet filter paper in petri dishes for 4-5 months. Germination occurred readily after this treatment ( $>80$ per cent germination), and the germinated seedlings were transferred to $7 \mathrm{~cm}$ (I. pallida) or $10 \mathrm{~cm}$ (I. capensis) pots. These progeny plants were then grown to maturity in greenhouses at the McGill University Phytotron, at which time the flower and stem phenotypes were scored.

The genetic control of corolla spotting in $I$. pallida was analysed by examining the progeny of: (1) self-fertilized parents of known phenotype $\left(S_{1}\right.$ families); and (2) crosses between parents of known phenotype $\left(F_{1}\right.$ families $)$. $S_{1}$ families were produced through the collection of seed from cleistogamous flowers. These were assembled from parents with unspotted corollas ( $n=10$ families), as well as from parents with spotted corollas $(n=$ 24 families). Families ranged in size from 9-36 progeny each $(\bar{x}=18 \cdot 9, \mathrm{SD}=8 \cdot 3) . \mathrm{F}_{1}$ progeny families were produced through crosses made with chasmogamous flowers. These included crosses between two parents each with spotted corollas ( $n=5$ families $)$, two parents each with unspotted corollas ( $n=2$ families), and two parents, one having spotted corollas and the other having unspotted corollas ( $n=9$ families). Family sizes for these crosses ranged from 8-129 progeny each $(\bar{x}=25, \mathrm{SD}=28 \cdot 8)$.

Parent plants from the $I$. pallida population exhibiting the yellow-white corolla colour polymorphism were less readily available, and thus only $S_{1}$ families were used to analyse the genetic control of this polymorphism. In collecting material from parents in the more uniform lighting conditions of the enclosure, we noted the existence of variation in the white corolla morph, with expression ranging from pure white to cream. We 

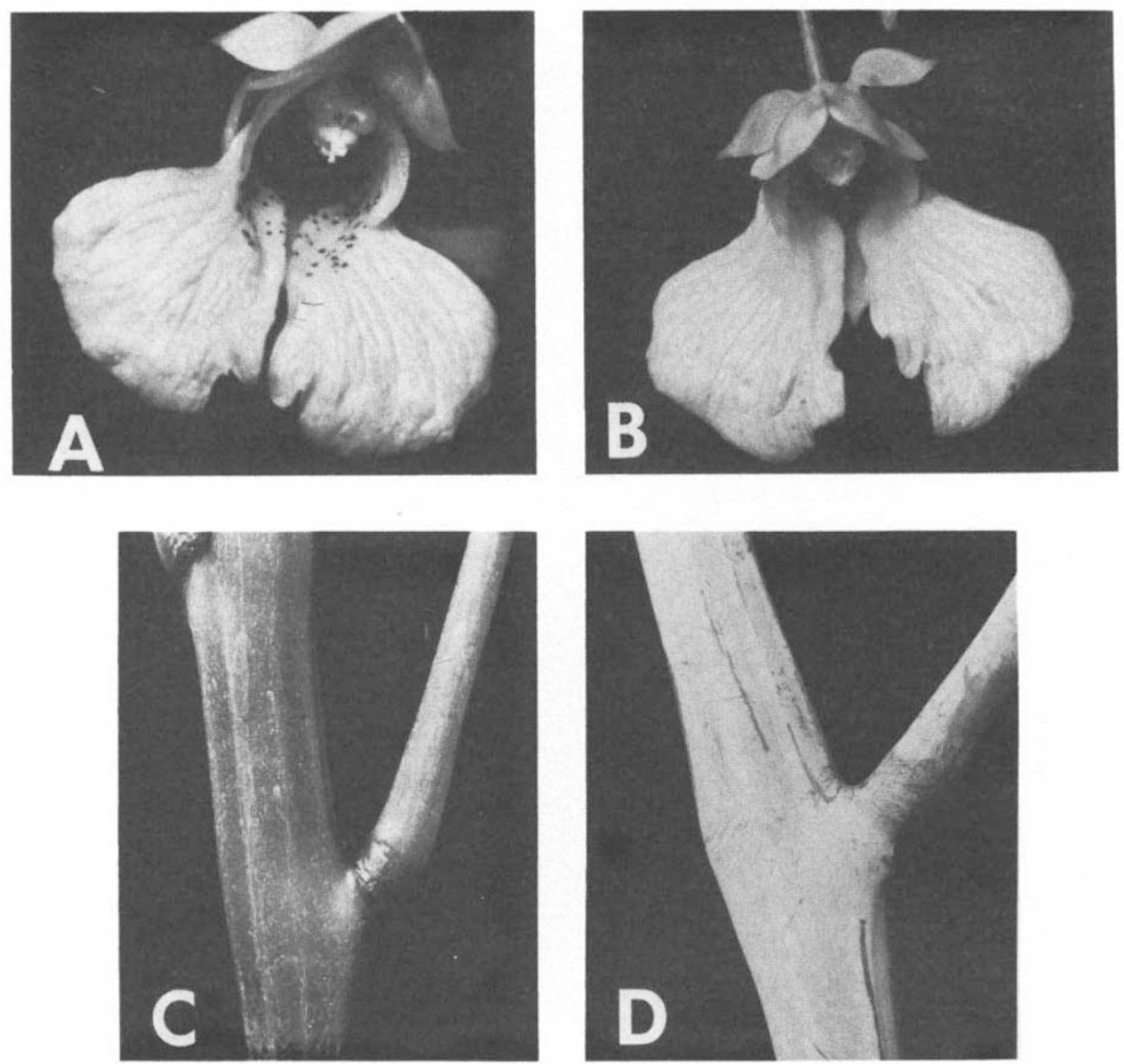

Figure 1 Polymorphisms in Impatiens pallida and I. capensis. A. Spotted corolla, I. pallida. B. Unspotted corolla, I. pallida. C. Waxless stem, I. capensis. D. Waxy stem, I. capensis.

coded all individuals lacking deep yellow corollas, as having white corollas, a practice which is most likely to correspond to that used in the field surveys of natural population samples. $S_{1}$ progeny were collected both from parents with yellow corollas ( $n=12$ families), and from parents with white corollas ( $n=6$ families). These families ranged in size from 4 to 22 progeny each $(\bar{x}=8 \cdot 6, \mathrm{SD}=5 \cdot 3)$.

Only small $S_{1}$ families of 5-15 progeny each were available for the study of stem waxiness in I. capensis. These family sizes were too small to allow formal Mendelian analysis, and so instead we conducted a preliminary genetic analysis based on the detection of segregation in the progenies of parents differing in the expression of this trait.

\section{Field sampling methods and data analysis}

For the study of spatial distribution of genotypes we sampled plants by laying out two belt transects in each of two large populations of I. pallida, and one belt transect in each of four populations of $I$. capensis (table 1). These transects were positioned so as to sample a large, uninterrupted section of each population. Transects were 1 or $2 \mathrm{~m}$ wide by up to $32 \mathrm{~m}$ long. Within a given transect, sampling was carried out at all points in a rectangular lattice of sampling points each separated by $10 \mathrm{~cm}$ within the rows of the lattice, and by $20 \mathrm{~cm}$ between the rows (fig. 2). The corolla or stem morph of the plant closest to (but no farther than $5 \mathrm{~cm}$ from) each lattice point was scored. Plants were removed from the ground after scoring to ensure that each plant was scored only once. When no plant (and in the case of I. pallida, when no chasmogamously flowering plant) was present at a lattice point, a missing value was entered in the data record for that spatial position (fig. 2). This process of sampling resulted in several hundred plants being scored for all polymorphisms in each population transect.

We employed spatial autocorrelation analysis (Sokal and Oden, 1978) in lieu of possible alternative analyses based on Wright's $F_{\mathrm{ST}}$ or Nei's $G_{\mathrm{ST}}$ statistics (Wright, 1951; Nei, 1973), because these 
Table 1 Populations and transects of Impatiens pallida and I. capensis studied

\begin{tabular}{|c|c|c|c|c|c|}
\hline \multirow[b]{2}{*}{ Species } & \multirow[b]{2}{*}{$\begin{array}{l}\text { Population/ } \\
\text { Transect }\end{array}$} & \multirow[b]{2}{*}{$\begin{array}{l}\text { Transect } \\
\text { dimensions }\end{array}$} & \multicolumn{3}{|c|}{ Frequencies (standard error) of: } \\
\hline & & & $\begin{array}{l}\text { Unspotted } \\
\text { corolla } \\
\text { morph }\end{array}$ & $\begin{array}{l}\text { White } \\
\text { corolla } \\
\text { morph }\end{array}$ & $\begin{array}{l}\text { Waxy } \\
\text { stem } \\
\text { morph }\end{array}$ \\
\hline I. pallida & $1 / \mathrm{A}$ & $27.6 \mathrm{~m} \times 2.0 \mathrm{~m}$ & $0.78(0.01)$ & $0.49(0.01)$ & $-\dagger$ \\
\hline I. pallida & $1 / \mathrm{B}$ & $32.4 \mathrm{~m} \times 2.0 \mathrm{~m}$ & $0.79(0.01)$ & $0.40(0.01)$ & 一† \\
\hline I. pallida & $2 / \mathrm{A}$ & $18.6 \mathrm{~m} \times 2.0 \mathrm{~m}$ & $0 \cdot 80(0.02)$ & 0 & -十 \\
\hline I. pallida & $2 / B$ & $19.0 \mathrm{~m} \times 2.0 \mathrm{~m}$ & $0.34(0.02)$ & 0 & $-\dagger$ \\
\hline I. capensis & $1 / \mathbf{A}$ & $16.0 \mathrm{~m} \times 1.0 \mathrm{~m}$ & $-\S$ & $-\S$ & $0.87(0.01)$ \\
\hline I. capensis & $2 / \mathrm{A}$ & $22.0 \mathrm{~m} \times 1.0 \mathrm{~m}$ & $-\S$ & $-\S$ & $0.52(0.02)$ \\
\hline I. capensis & $3 / \mathrm{A}$ & $24.0 \mathrm{~m} \times 1.0 \mathrm{~m}$ & $-\S$ & $-\S$ & $0.56(0.01)$ \\
\hline I. capensis & $4 / \mathrm{A}$ & $12.0 \mathrm{~m} \times 1.0 \mathrm{~m}$ & $-\S$ & $-\S$ & $0.83(0.02)$ \\
\hline
\end{tabular}

$\S$ scored only in Impatiens pallida.

† Scored only in Impatiens capensis.

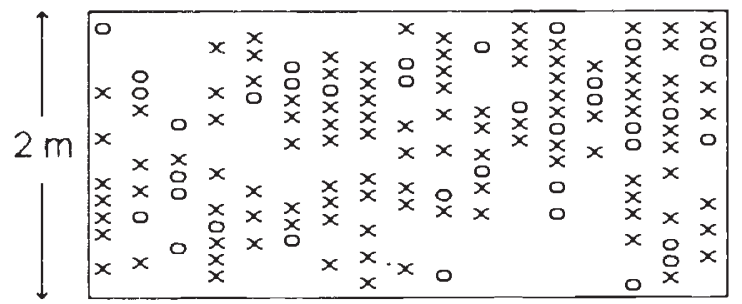

Figure 2 Distribution of individuals with yellow $\left(x^{*} s\right)$ and white (circles) corollas in a section of transect A, population 1 of Impatiens pallida at Mont St. Hilaire, Québec, Canada. Blanks in diagram represent grid points with missing plants or plants without chasmogamous flowers. Each row contains 21 sampling points separated by $10 \mathrm{~cm}$. Points in adjacent rows separated by $20 \mathrm{~cm}$.

latter methods use data obtained from the genotypes at single loci. Our genetic analysis of the polymorphisms suggests that the traits studied have a more complex genetic basis (see below). Moreover, spatial autocorrelation analysis offers a powerful statistical approach for detecting nonrandom spatial distribution of genotypes at small scales, since all pairs of individuals contribute to information about the spatial distribution pattern (Sokal and Oden, 1978; Epperson, 1989).

In essence, spatial autocorrelation analysis involves examining the dependence of a given morph at each sampling point on the morph present at other sampling points. Population subdivision, is indicated by positive spatial autocorrelation among identical morphs at small interpoint distances coupled with decline to zero and negative autocorrelation values at larger interpoint distances (Sokal and Oden, 1978). In applying the statistical methods to the data collected in this investigation, the total number of joins between pairs of plants were counted for each interpoint distance in the sampling lattice (referred to hereafter as a distance-class; e.g., the $10 \mathrm{~cm}$ distance class, $20 \mathrm{~cm}$ distance class, $30 \mathrm{~cm}$, etc.). We also counted the numbers of joins between identical morphs (homotypic joins) and between non-identical morphs (heterotypic joins) for each polymorphism. For instance, in the case of the yellow-white corolla colour polymorphism in $I$. pallida, a count was made of the numbers of joins involving pairs of plants each with yellow corollas, pairs of plants each with white corollas, and pairs involving one plant with yellow corollas and one plant with white corollas. This was done for each distance class, and the observed counts were compared to those expected given random spatial distribution of the polymorphisms. Thus, for example, under the assumption of random spatial distribution of the corolla colour morphs, the expected number of joins between plants with white corollas at distance class $i$ is $\mu_{\mathrm{wW}_{i}}=$ $\left[Z_{i} n_{\mathrm{W}_{i}}\left(n_{\mathrm{W}_{i}}-1\right)\right] /\left[2^{*} n_{i} *\left(n_{i}-1\right)\right]$, where $Z_{i}$ is two times the total number joins between all pairs of points at distance class $i$ in which plants were present, $n_{\mathrm{W} i}$ is the number of plants with white corollas for distance class $i$, and $n_{i}$ is the total number of plants for distance class $i$ (Sokal and Oden, 1978). The expected numbers of joins between plants with different coloured corollas at distance class $i$, under the assumption of random spatial distribution of morphs, is $\mu_{Y W_{i}}=$ $\left[Z_{i} n_{Y_{i}} n_{\mathrm{W}_{i}}\right] /\left[n_{i}{ }^{*}\left(n_{i}-1\right)\right]$, where $n_{\mathrm{Y} i}$ is the number of plants with yellow corollas for distance class $i$. Observed and expected numbers of homotypic and heterotypic joins were compared statistically at each distance class via calculation of a standard- 
ized normal deviate (SND) (Sokal and Oden, 1978). Correlograms (graphs of SND versus distance class) are used below to summarize the results of these analyses.

\section{RESULTS}

\section{Genetic studies of the flower and stem polymorphisms}

None of the I. pallida parents with unspotted corollas produced segregating $S_{1}$ progenies, while 8 of the $24 \mathrm{~S}_{1}$ families from parents with spotted corollas showed segregation (table 2). Segregation ratios in each of the individual families, as well as the pooled data, conformed to a $3: 1$ (spotted:unspotted) ratio, though some individual families conformed better to a 9:7 (spotted:unspotted) ratio (table 2 ).

Table 2 Segregation of corolla spotting in the $S_{1}$ progeny of spotted parents in Impatiens pallida

\begin{tabular}{|c|c|c|c|c|}
\hline \multirow{2}{*}{$\begin{array}{l}\text { S1 } \\
\text { family }\end{array}$} & \multicolumn{2}{|c|}{ Corolla spotting } & \multirow[b]{2}{*}{$\chi^{2}(3: 1)$} & \multirow[b]{2}{*}{$\chi^{2}(9: 7)$} \\
\hline & Spotted & Unspotted & & \\
\hline $\mathrm{J} 5$ & 7 & 5 & 1.77 & 0.02 \\
\hline J9 & 25 & 6 & 0.53 & $7 \cdot 50 * *$ \\
\hline J30 & 17 & 9 & $1 \cdot 28$ & 0.88 \\
\hline $\mathrm{H} 464 \mathrm{a}$ & 15 & 3 & 0.66 & $5 \cdot 37^{*}$ \\
\hline $\mathrm{H} 464 \mathrm{~b}$ & 6 & 3 & $0 \cdot 33$ & 0.40 \\
\hline $\mathrm{H} 471 \mathrm{a}$ & 13 & 4 & 0.02 & $2 \cdot 82$ \\
\hline $\mathrm{H} 482$ & 13 & 9 & $2 \cdot 97$ & 0.07 \\
\hline $\mathrm{H} 484$ & 16 & 3 & 0.86 & $6 \cdot 04^{*}$ \\
\hline Sum & 112 & 42 & $0.42 \S$ & $-\dagger$ \\
\hline
\end{tabular}

$* P<0.05$.

** $P<0.01$.

$\S$ Deviation $\chi^{2}[7]=8.44, P>0.05$; pooling of family data justified.

$\dagger$ Deviation $\chi^{2}[7]=23.09, P<0.01$; pooling of family data not justified.

The $F_{1}$ families produced by intercrossing two spotted parents produced only spotted progeny, while the $F_{1}$ families produced by intercrossing two unspotted parents produced only unspotted progenies. Five $F_{t}$ families from the crosses of spotted $\times$ unspotted parents, however, showed segregating progenies. In four of these families, individual and pooled segregation ratios conformed to a 1:1 (spotted: unspotted) ratio (table 3 ). The segregation ratio of the fifth segregating family conformed poorly to a $1: 1$ ratio, but conformed well to a $3: 1$ (spotted:unspotted) ratio $\left(\chi^{2}=\right.$ $1 \cdot 49, P>0 \cdot 05)$. Together the $S_{1}$ and $F_{1}$ cross results support the genetic hypothesis of two-factor, com-
Table 3 Segregation of corolla spotting in $F_{1}$ progeny of crosses of spotted $\times$ spotted parents in Impatiens pallida

\begin{tabular}{|c|c|c|c|}
\hline \multirow[b]{2}{*}{$F_{1}$ family } & \multicolumn{2}{|c|}{ Corolla spotting } & \multirow[b]{2}{*}{$\chi^{2}(1: 1)$} \\
\hline & Spotted & Unspotted & \\
\hline $\mathrm{Sp} 11 \times \mathrm{Sp} 12$ & 75 & 54 & $3 \cdot 41$ \\
\hline $\operatorname{Sp} 27 \times \operatorname{Sp} 88$ & 12 & 9 & 0.43 \\
\hline $\mathrm{Sp} 36 \times \mathrm{Sp} 48$ & 10 & 18 & $2 \cdot 29$ \\
\hline Sp $91 \times \operatorname{Sp} 10$ & 10 & 6 & $1 \cdot 00$ \\
\hline Sp65 $\times$ Sp 89 & 23 & 4 & $13 \cdot 37^{* * *, \S}$ \\
\hline
\end{tabular}

*** $P<0.005$.

$\S \chi^{2}$ against a null hypothesis of $3: 1$ for this family $=1.49$ $(P>0.05)$.

plementary control of corolla spotting (Grant, 1975), i.e., corolla spotting in I. pallida appears to be determined by two unlinked loci, each with dominant alleles, and with one dominant allele at each locus required for the spotting trait to be expressed. This hypothesis provides the most parsimonious explanation of the probable parental genotypes used in the crosses and the observed segregation ratios in their progenies.

The results from the analysis of the yellowwhite corolla colour polymorphism in $I$. pallida revealed no segregation in $S_{1}$ families from parents with white corollas. Six of the families from parents with yellow corollas showed segregation (table 4). Segregation ratios in $S_{1}$ progeny families conform either to $3: 1$ or $9: 7$ (yellow: white) ratio. As in the case of corolla spotting, it seems likely that two unlinked loci determine expression of the trait, with one dominant allele at each locus required for the yellow corolla trait to be expressed.

Table 4 Segregation of corolla colour in the $S_{1}$ progeny of yellow-flowered parents in Impatiens pallida

\begin{tabular}{|c|c|c|c|c|}
\hline \multirow{2}{*}{$\begin{array}{l}\mathrm{S}_{1} \\
\text { family }\end{array}$} & \multicolumn{2}{|c|}{ Corolla colour } & \multirow[b]{2}{*}{$\chi^{2}(3: 1)$} & \multirow[b]{2}{*}{$\chi^{2}(9: 7)$} \\
\hline & Yellow & White & & \\
\hline $\mathrm{H} 82$ & 4 & 4 & $2 \cdot 67$ & $0 \cdot 13$ \\
\hline $\mathrm{H} 464 \mathrm{a}$ & 9 & 9 & $6 \cdot 00^{*}$ & $0 \cdot 29$ \\
\hline $\mathrm{H} 464 \mathrm{~b}$ & 6 & 4 & $1 \cdot 20$ & 0.06 \\
\hline $\mathrm{H} 471 \mathrm{a}$ & 15 & 7 & 0.54 & $1 \cdot 27$ \\
\hline $\mathrm{H} 482$ & 14 & 3 & 0.49 & $4 \cdot 71^{*}$ \\
\hline B22 & 7 & 2 & 0.04 & 1.69 \\
\hline
\end{tabular}

$* P<0 \cdot 05$.

With regard to linkage anong the loci coding for corolla spotting and corolla colour, in the four $S_{1}$ families which segregated for both the spottedunspotted and yellow-white polymorphisms (e.g., families H464a, H464b, H482, and H484), there 
was no strong evidence of non-independent segregation of the two polymorphisms as evidenced by Chi-square analysis of morph frequencies in $2 \times 2$ tables of joint segregation $\left(\chi^{2}[1]=0 \cdot 60,2 \cdot 13,0 \cdot 68\right.$, $0 \cdot 39$, respectively, for the four families listed above).

For the waxless-waxy stem polymorphism in I. capensis, segregation was observed only in families of waxless-stemmed parents. From this result, we hypothesize that at least one gene locus codes for stem waxiness, with the gene(s) coding for waxless stems being dominant to the gene(s) for waxy stems.

\section{Spatial autocorrelation of flower and stem morphs in I. pallida and I. capensis populations}

Below we describe separately the results from the spatial autocorrelation analysis of each polymorphism, beginning with the spotted-unspotted corolla polymorphism. At short distance classes in both populations of $I$. pallida, there were significant excesses of at least one type of homotypic join, and significant deficits of heterotypic joins involving the spotted-unspotted corolla polymorphism. At larger distance classes there were significant excesses of heterotypic joins, and significant deficits of at least one class of homotypic join (fig. 3). In two of the samples, excess homotypic joins at short diatances were found only for the unspotted corolla morph. In one sample, excess homotypic joins at short distances were found for both morphs, and in the remaining case, excess homotypic joins at short distances were found only for the spotted corolla morph (fig. 3).

Excesses of homotypic joins at short distances are interpreted here and below as patches of the morph in question (Sokal and Oden, 1978). In substructured populations, excesses of heterotypic joins are expected at larger distances when the interpoint sampling distance spans patches of two different morphs. Instances of multiple excesses of homotypic joins occurring at different spatial scales, such as seen in with the spotted-unspotted corolla polymorphism in population 2 of I. pallida, are not unexpected since with large interpoint sampling distances, two separate patches of the same type may be sampled. Using the first $x$-intercept of the correlogram as an indicator of the average length of a patch, and focussing on the morph which is true-breeding when self-fertilized (i.e. the unspotted corolla morph; see above) (Sokal, 1979; Epperson and Clegg, 1986), it can be seen that patch length ranged from approximately 2 to $4 \mathrm{~m}$.
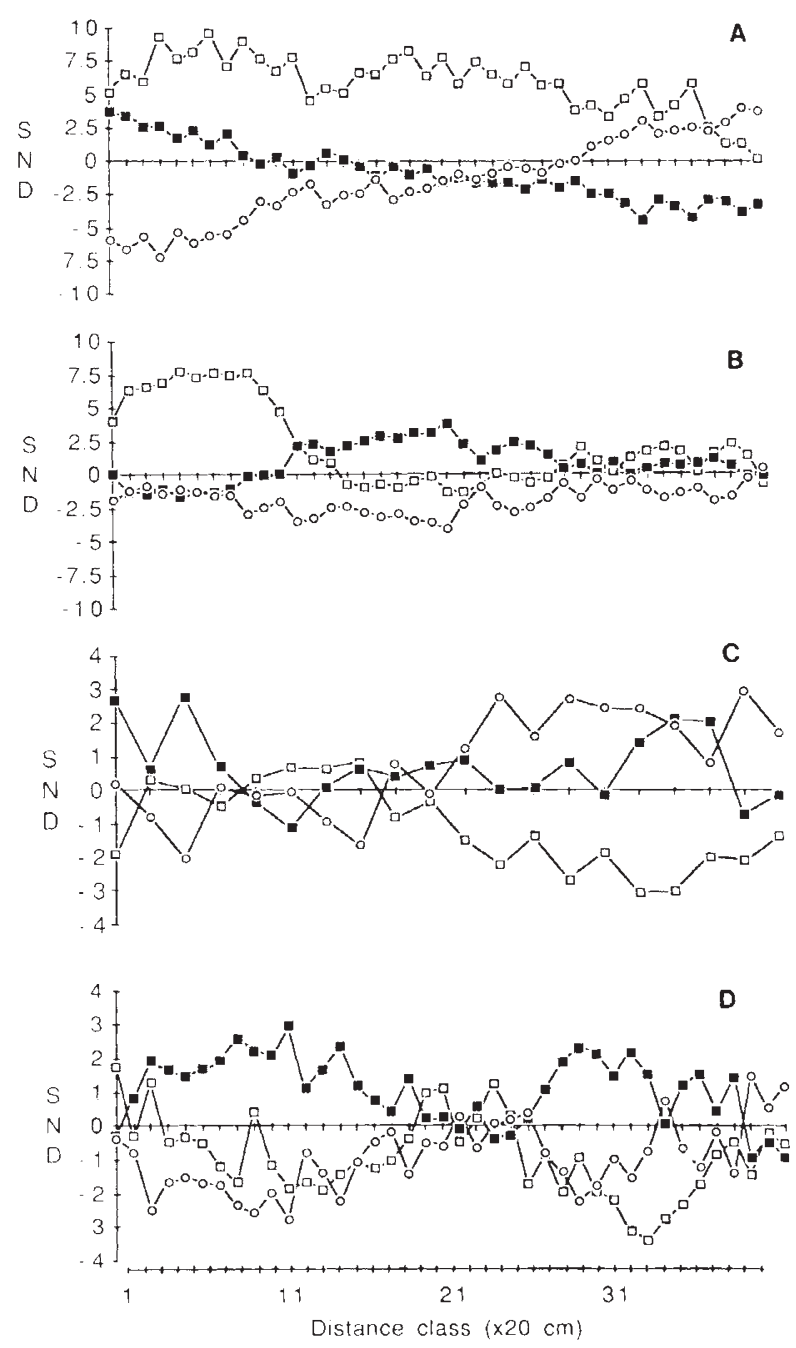

Figure 3 Correlograms of standard normal deviates (SND) for unspotted and spotted corollas in Impatiens pallida. A. Population 1, transect A. B. Population 1, transect B. C. Population 2, transect A. D. Population 2, transect B. Closed squares (unspotted-unspotted joins), open squares (spotted-spotted joins), circles (unspotted-spotted joins).

The yellow-white corolla colour polymorphism was present only in population 1 of I. pallida. Each of the transect samples in that population showed significant excesses of homotypic joins involving the white corolla morph at short distance classes (fig. 4). In one of the samples, both classes of homotypic joins were in excess at short distance classes. Patch length as estimated using the procedure described above for the true-breeding (i.e., white corolla) morph was between 2 and $3 \mathrm{~m}$ (fig. 4).

For the waxless-waxy stem polymorphism in I. capensis, all four populations studied showed 

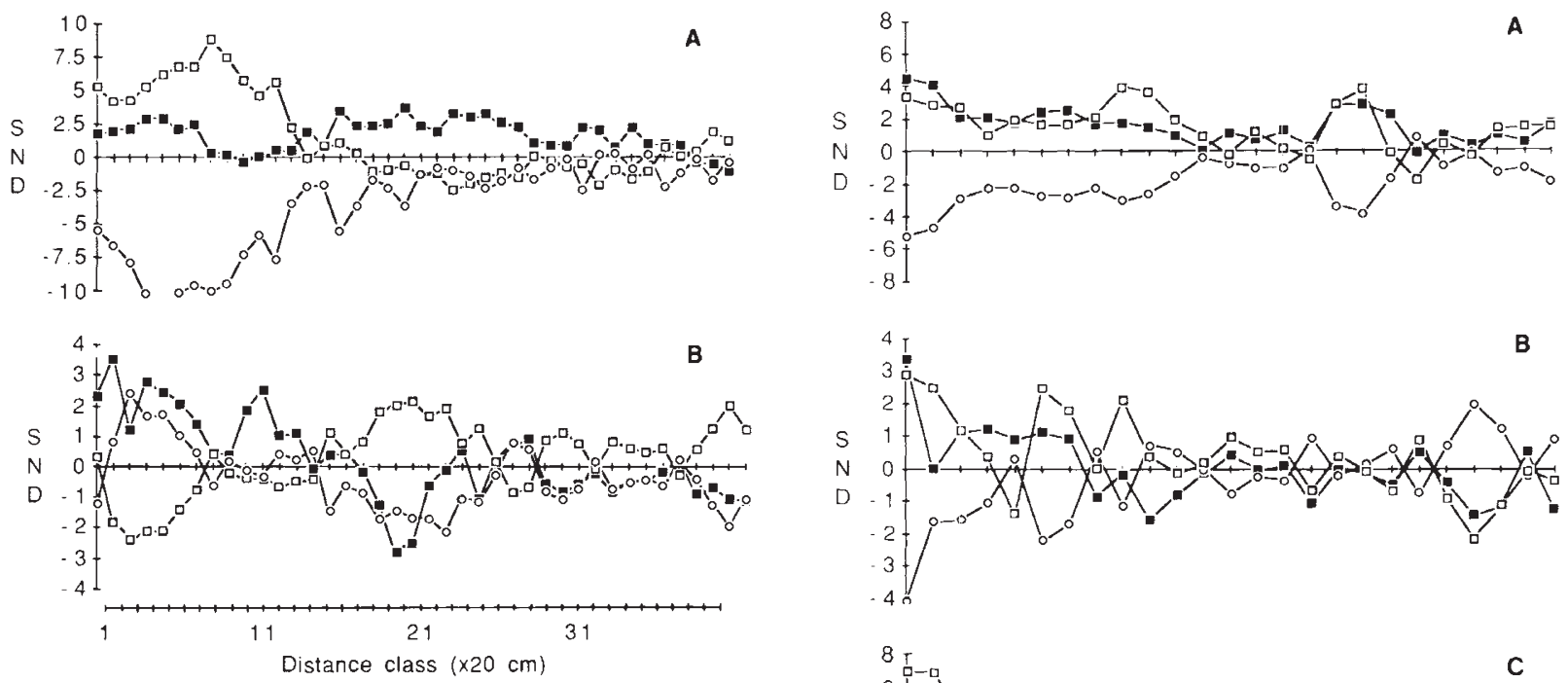

Figure 4 Correlograms of standard normal deviates (SND) for white and yellow corollas in Impatiens pallida. A. Population 1, transect A. B. Population 1, transect B. Closed squares (white-white joins) open squares (yellow-yellow joins), circles (white-yellow joins)

substructuring, with excesses of at least one class of homotypic join, and deficits of heterotypic joins at short distance classes (fig. 5). Patch length for the true-breeding (i.e., waxy) morph was approximately $1 \mathrm{~m}$ or less.

\section{DISCUSSION}

Two-factor, complementary control of corolla spotting and corolla colour has also been reported in other species (Clausen, 1951; Grant, 1975). Our hypothesis with regard to the genetic control of these traits should, however, be viewed as preliminary as it is based on small sample sizes and few types of crosses. More complex genetic hypotheses cannot be excluded with certainty. Additional genetic studies will also be required before a precise genetic hypothesis can be put forward for the control of stem waxiness, though it seems likely from the data presented above that a genetic polymorphism underlies the variation observed.

At present we have no detailed information to suggest either the presence or absence of selection at the loci responsible for the flower and stem polymorphisms observed in these populations. Casual investigation of the distribution of seed set per fruit and of plant biomass have revealed no significant differences between the yellow and

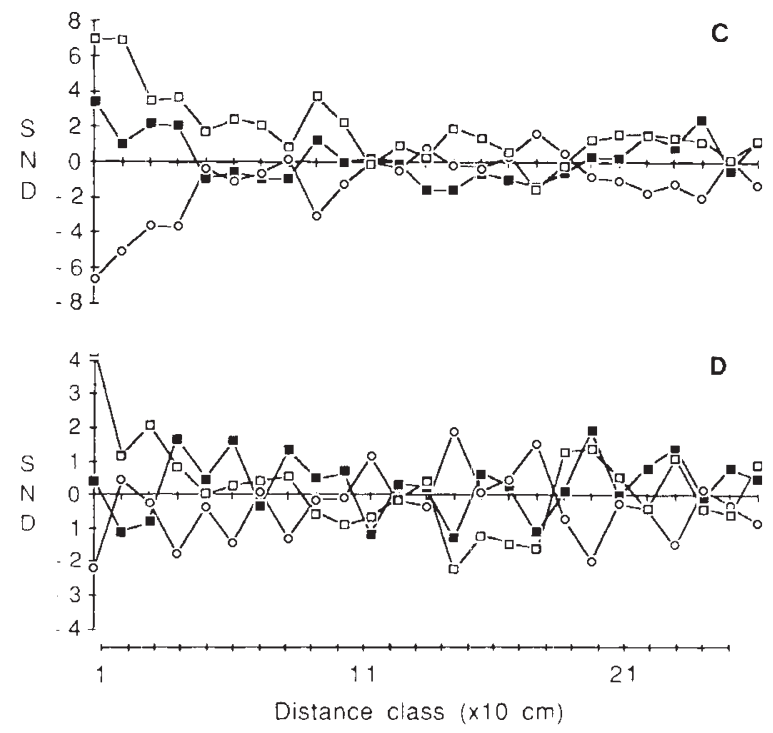

Figure 5 Correlograms of standard normal deviates (SND) for waxy and waxless stems in Impatiens caoensis. A. Population 1. B. Population 2. C. Population 3. D. Population 4. Closed squares (waxy-waxy joins), open squares (waxless-waxless joins), circles (waxy-waxless joins).

white corolla morphs of I. pallida (Schoen, unpublished data). It is notable that both the spottedunspotted and yellow-white polymorphisms in $I$. pallida are apparently widespread in eastern North America (Fernald, 1950).

The type of patch structure observed within the populations of I. pallida and I. capensis at Mont St. Hilaire could, in theory, have its basis in spatially-varying selection, limited gene flow, or both. Small scale differentiation within populations that is correlated with microenvironmental variation has been reported for a number of plant 
species (Antonovics and Bradshaw, 1970; Linhart, 1974; Silander and Antonovics, 1979; Antlfinger, 1981). Such correlation suggests the past and continuing action of selection in creating and maintaining small-scale differentiation. On the other hand, Turner, Stephens, and Anderson (1982), Sokal and Wartenburg (1983), and Bos and van der Haring (1988) have deomonstrated that patch structure develops rapidly under isolation-by-distance models, and does not require spatiallyheterogeneous selection. After 50 generations, patch length approaches an equilibrium which is functionally related to Wright's neighbourhood size (Wright, 1969; Epperson and Clegg, 1986). When selection interacts with local gene dispersal, the result may be either enhancement of diminution of patch structure. In particular, when selection acts on a polymorphism independently of location, patch structure can be eroded (Epperson, 1989). On the other hand, when fitnesses at a polymorphic locus are dependent on location, limited gene dispersal can enhance patch structure (Maynard Smith, 1966; Dickinson and Antonovics, 1973).

Gene dispersal distances in the Impatiens species studied here appear to be quite limited, as judged by observations of seed dispersal (Schmitt, Ehrhardt and Swartz, 1985; G. Bell, personal communication) and pollinator movements among chasmogamous flowers (Dubé, 1988). A more important factor contributing to reduced pollen dispersal distance in these species is the large proportion of seeds that are produced as a result of cleistogamous self-pollination. This proportion can comprise virtually all seeds that are produced in some of the populations studied. We have no information at present on possible assortative mating mediated through pollinator preference for one flower morph, as reported by Brown and Clegg (1984) in I. purpurea, though if such assortative mating were to occur in conjunction with limited gene dispersal, this would accentuate any already existing patch structure.

Given the above observational and anecdotal evidence pertaining to gene flow distances, together with the theoretical expectation that limited gene flow can promote population substructure, one might predict a priori that populations of $I$. pallida and I. capensis should exhibit patch structure for the polymorphisms. The results of this study indicate that there is, indeed, substructuring of genotypes coding for these polymorphisms. Such substructuring is most apparent and consistently observed for the morph types which are true-breeding and which, therefore, comprise the more genetically homogeneous phenotypic class within each polymorphism. These patches can be equated to patches of the more homozygous morph. If spatially-varying selection were responsible for the existence of patches, this would require the existence of areas within each population where one morph or the other was selectively favoured. Moreover, the relative constancy of patch size within and among polymorphisms suggests that in order for the observed spatial patterns to be maintained primarily by selection, the scale of spatially-heterogeneous selection, or grain of the environmental variation (sensu Levins, 1968), would have to be roughly equivalent across polymorphisms. There is no evidence from the physical nature of the habitats studied that this type of spatially-structured selection could operate. A tentative conclusion at present, is that patch structure in the case of these polymorphisms is due primarily to limited gene dispersal.

In earlier studies of some of these same population samples, we have discovered significant spatial heterogeneity among plots (separated by several metres) in both the direction and magnitude of phenotypic selection coefficients associated with quantitative traits such as cotyledon area, timing of leaf production, and characteristics related to growth rate (Stewart and Schoen 1987). Such spatial heterogeneity of selection when coupled with limited gene dispersal and the type of population substructure observed here could lead to local adaptation and population differentiation over small distances (Via and Lande, 1985). Schemske (1984) in fact has reported that samples collected from $30-50 \mathrm{~m}$ apart in two populations of 1 . pallida from Illinois, U.S.A. were differentiated for a number of traits, and he suggests that heterogeneity of selection and limited gene flow may be responsible for this differentiation. While the results reported by Stewart and Schoen (1987) together with the present study are not sufficiently complete to demonstrate that within-population differentiation in I. pallida is indeed the result of local adaptation and restricted gene flow, they suggest that this scenario is consistent with the population and reproductive biology of the species.

Acknowledgements We thank Cremilda Dias, Steven Stewart and Jonathan Brassard for assistance, and the 1988 class of Biology 331 A at McGill University for help in censusing the populations of $I$. capensis. We also thank Dr Graham Bell for sharing with us his data on the genetic control of stem waxiness in $I$. capensis. This project was supported by a research grant from the Natural Sciences and Engineering Council (NSERC) of Canada to DJS and by a NSERC undergraduate research student award to RGL. 


\section{REFERENCES}

ANTLFINGER, A. E. 1981. The genetic basis of microdifferentiation in natural and experimental populations of Borrichia frutescens in relation to salinity. Evolution, 35, 1056-1069.

ANTONOVICS, J. AND BRADSHAW, A. D. 1970. Evolution in closely adjacent plant populations. VIII. Clinal patterns at a mine boundry. Heredity, 25, 349-362.

BOS, M. AND VAN DER HARING, E. 1988. Gene fiow in Plantago. II. Gene flow pattern and population structure. A simulation study. Heredity, 61, 1-11.

BRADSHAW, A. D. 1984 Ecological significance of genetic variation between populations. In Dirzo, R. and Sarukhan, J. (eds) Perspectives on Plant Population Ecology, Sinauer, Sunderland, Mass, pp. 213-228.

BROWN, B. A. AND CLEGG, M. T. 1984. Influence of flower colour polymorphism on genetic transmission in a natural population of the common morning glory. Evolution, 38, 796-803.

Clausen, J. 1951. Stages in the Evolution of Plant Species. Cornell Univ. Press, Ithaca.

DEWEY, S. E. AND HEYWOOD, J. S. 1988. Spatial genetic structure in a population of Psychotria nervosa. I. Distribution of genotypes. Evolution, 43, 834-838.

DICKINSON, H. AND ANTONOVICS, J. 1973. Theoretical considerations of sympatric divergence. Amer. Natur., 107, 256-274.

DUBE, D. 1988. Flight path of pollinators foraging on Impatiens. Decision rules and their implications for gene flow. M.Sc. Thesis, McGill University, Montreal.

ELlSTRAND, N. C., TORRES, A. M. AND LEVIN, D. A. 1978. Density and the rate of apparent outcrossing in Helianthus annus (Asteraceae). Syst. Bot., 3, 403-407.

ENNOS, R. A. 1985. The mating system and genetic structure in a perennial grass, Cynosurus cristatus L. Heredity, 55, 121126.

ENNOS, R. A. AND CLEGG, M. T. 1982. Effect of population substructuring on estimates of outcrossing rate in plant populations. Heredity, 48, 283-292.

EPLING, C. AND DOBZHANSKY, T. 1942. Genetics of natural populations. VI. Microgeographic races in Linanthus parryae. Genetics, 27, 317-332.

EPPERSON, B. K. 1989. Spatial patterns of genetic variation within plant populations. In Brown, A. H. D., Clegg, M. T., Kahler, A. L. and Weir, B. S. (eds) Population Genetics and Germplasm Resources in Crop Improvement. Sinauer, Sunderland, Mass.

EPPERSON, B. K. AND CLEGG, M. T. 1986. Spatial-autocorrelation analysis of flower colour polymorphisms within structured populations of morning glory (Ipomoea purpurea). Amer. Natur., 128, 840-858.

EPPERSON, B. K. AND ÁLLARD, R. W. 1989. Spatial-autocorrelation analysis of the distribution of genotypes within populations of lodgepole pine. Genetics, 121, 369-377.

FERNALD, M. L. 1950. Gray's Manual of Botany, 8th edn. D. Van Nostrand, New York.

HAMRICK, J. L. AND ALLARD, R. W. 1972. Microgeographical variation in allozyme frequencies in Avena barbata. Proc. Natl Acad. Sci. USA, 69, 2100-2104.

GRANT, V. 1975. Genetics of Flowering Plants. Columbia Univ. Press, New York.

LEVINS, R. 1968. Evolution in Changing Environments. Princeton Univ. Press, Princeton.
LINHART, Y. 1974. Intra-population differentiation in annual plants. I. Veronica peregrina IL. raised under non-competitive conditions. Evolution, 28, 232-243.

MAYCOCK, P. F. 1961. Botanical studies on Mont St. Hilaire, Rouville County, Québec. General description of the area and floristic survey. Can. J. Bot., 39, 1293-1325.

MAYNARD SMith, J. 1966. Sympatric speciation. Amer. Natur., $100,637-650$.

NEI, M. 1973. Analysis of gene diversity in subdivided populations. Proc. Natl Acad. Sci. USA, 70, 3321-3323.

RITLAND, K. 1985. The genetic-mating structure of subdivided populations. I. Open-mating model. Theoret. Popul. Biol., $27,51-74$.

SCHAAL, B. A. 1975. Population structure and local differentiation in Liatris cylindracea. Amer. Natur., 109, 511-528.

SCHEMSKE, D. W. 1978. Evolution of reproductive characteristics in Impatiens (Balsaminaceae): the significance of clesitogamy and chasmogamy. Ecology, 59, 596-613.

SCHEMSKE, D. W. 1984. Population structure and local selection in Impatiens pallida (Balsaminaceae), a selfing annual. Evolution, 38, 817-832.

SCHMITT, J. EHRHARDT, D. AND SWARTZ, D. 1985. Differential dispersal of self-fertilized and outcrossed progeny in jewelweed (Impatiens capensis). Amer. Natur., 126, 570-575.

SILANDER, J. A. AND ANTONOVICS, J. 1979. The genetic basis of the ecological amplitude of Spartina patens. I. Morphometric and physiological traits. Evolution, 33, 11141127.

SOKA.L, R. R. 1979. Ecological parameters inferred from spatial correlograms. In Patil, G. P. and Rosenzweig, M. L. (eds) Contemporary Quantitative Ecology and Related Ecometrics International Cooperative Publishing House, Fairland, Maryland, pp. 167-196.

SOKAL, R. R. AND ODEN, N. L. 1978. Spatial autocorrelation in biology. 1. Methodology. Biol. J. Linn. Soc., 10, 199-228.

SOKAL, R. R. AND WARTENBURG, D. E. 1983. A test of spatial autorelation analysis using an isolation-by-distance model. Genetics, 105, 219-237.

STEWART, S. C. AND SCHOEN, D. J. 1987. Pattern of phenotypic viability and fecundity selection in a natural population of Impatiens pallida. Evolution, 41, 1290-1301.

TURNER, M. E., STEPHENS, J. C. AND ANDERSON, W. W. 1982. Homozygosity and patch structure in plant populations as a result of nearest-neighbor pollination. Proc. Natl Acad. Sci. USA, 79, 203-2907.

VIA, S. AND LANDE, R. 1985. Genotype-environment interaction and the evolution of phenotypic plasticity. Evolution, 39, 505-522.

WALLER, D. M. 1980. Environmental determinates of outcrossing in Impatiens capensis. Evolution, 34, 747-761.

WASER, N. M. 1987. Spatial genetic heterogeneity in a population of the montane perennial plant Delphinium nelsonii. Heredity, 58, 249-256.

WRIGHT, S. 1943. Analysis of local variability of flower colour in Linanthus parryae. Genetics, 28, 139-156.

Wright, s. 1951. The genetical structure of populations. Ann. Eugenics, 15, 323-354.

WRIGHT, S. 1969. Evolution and the Genetics of Populations. Vol. 2. The Theory of Gene Frequencies. Univ. Chicago Press, Chicago.

WRIGHT, S. 1978. Evolution and Genetics of Populations, Vol. 4. Variability Within and Among Natural Populations. Univ. Chicago Press, Chicago. 